Original Research

\title{
Evaluating Hydrological and Environmental Effects for Low-Impact Development of a Sponge City
}

\author{
Jiake Li ${ }^{1 *}$, Menghua Ma1, Yajiao Li², Chenning Deng ${ }^{3}$, Baozhu Pan ${ }^{1}$ \\ 'State Key Laboratory of Eco-Hydraulic Engineering in Arid Area, Xi'an University of Technology, Xi'an, China \\ ${ }^{2}$ School of Architecture and Civil Engineering, Xi' an University of Science and Technology, Xi'an, China \\ ${ }^{3}$ College of Water Sciences, Beijing Normal University, Beijing, China
}

Received: 26 February 2019

Accepted: 12 May 2019

\begin{abstract}
The rapid urbanization and high density of urban populations has resulted in increasing hydrological and environmental problems. A distribution model was established for an urban area located in Xixian New Area in Shaanxi Province, China to evaluate the hydrological and environmental effects of low-impact development (LID). The results for all simulated rainfall events show that: (1) LID mode could effectively control urban rainstorm runoff and reduce the peak flow, total amounts of runoff and pollution load. Compared with traditional development (TD), the runoff reduction rates were increased by $18.3-34.7 \%$, and total amounts of suspended solids (SS), chemical oxygen demand (COD), total phosphorus (TP), and total nitrogen (TN) were reduced by $42.4 \sim 80.3 \%$. (2) The peak concentration was reduced and the appearance time was delayed under LID mode. Compared with TD mode, the reduction rates of all pollutant loads had been remarkably reduced. However, the reduction effects on rainfall runoff and its pollution loads gradually decreased with the design rainfall recurrence periods increased. (3) The linear models between pollution load reduction amount and runoff reduction amount were established, which can be used to predict urban non-point source pollution load for a rainfall event or a given year.
\end{abstract}

Keywords: SWMM, LID, rainfall runoff, non-point source (NPS) pollution, linear model

\section{Introduction}

With rapid urbanization, the urban permeable underlying surface has sharply decreased. Rainfall runoff appears quickly and is discharged through pipelines. Many pollutants in rainfall runoff enter the receiving water body through the urban drainage

*e-mail: xaut_ljk@163.com system. The obvious effects of urbanization are the significant increase of surface runoff companied by flood peak flow, the increase of the occurrence frequency of urban water-logging and non-point source (NPS) pollution, which endangers the safety of the urban environment [1-3]. Aiming at the problems of waterlogging and NPS pollution, the concept of "sponge city" was first proposed in China in April 2012 [4]. "Sponge city" means that a variety of measures, such as source reduction, intermediate diversion, and terminal regulation and so on, are used to achieve a benign 
hydrological cycle of urban area and improve the ability of infiltration, regulation, purification, utilization and discharge of runoff for maintaining or restoring the city's "sponge" function. Its construction concept is mainly based on LID - a new strategy for urban water environmental protection and sustainable development of storm water management in the international community that plays an important role in alleviating waterlogging and NPS pollution [5-6]. It is necessary to deeply understand, accurately predict and simulate the process of rainfall runoff and NPS pollution for studying urban waterlogging and NPS pollution. In recent years, different stormwater management models such as SWMM, Mike Urban, Info Works CS, SUSTAIN, STORM, and MOUSE, have been developed in many developed countries [7-10]. SWMM is widely used in urban stormwater management and NPS pollution control [11]. It is suitable for various land utilization conditions with high accuracy [12]. Meanwhile, the transfer process of rainfall runoff and pollution load can be simulated through establishing a rainfall-runoff model using SWMM. In the past few years the SWMM model has been used in many countries for urban water environmental research. Guan et al. used SWMM to compare the control effects of water quantity and quality under different development modes [13]. The flood risk of different LID technologies for a region with high rainfall intensity in coastal areas of southern Brazil were assessed by using SWMM [14]. SWMM was used by Tsihrintzis and Hamid to simulate water quantity and quality of urban stormwater runoff from four relatively small sites with specific predominant land use [15]. Water resources include the two aspects of water quantity and water quality, which are interdependent and indispensable. Water quantity and quality were evaluated separately when evaluating regional water resources. It had great inconvenience for management and protection of water resources because urban rainfall runoff and NPS pollution are interdependent [16]. Due to the complexity of water quantity and quality changing with time and space, it is of great significance to study the interaction between urban rainfall runoff and NPS pollution.

A pilot area of sponge city construction located in Xixian New Area in Shaanxi Province, China, was taken as the study area. The objectives of this work are: (i) to simulate and evaluate the runoff amount and NPS pollution load reduction effects of LID under different design rainfall scenarios through establishing a SWMM model for the study area. (ii) To quantify and analyze the concentration removal effects and change process of LID based on a typical drainage partition. And (iii) to explore and establish the linear model of runoff reduction amount and NPS pollution load reduction amount so as to predict the NPS pollution load reduction amount under different runoff reduction rates, which can provide a reference for the development and construction for a sponge city LID system.

\section{Materials and Methods}

\section{Overview of Study Area}

The study area is located in Xixian New Area in Shaanxi Province, China. This region has a total area of $23.65 \mathrm{~km}^{2}$ and belongs to a warm temperate semi-arid and semi-humid monsoon climate zone. The proportion of impermeable area was $54.7 \%$. The average annual precipitation in this region is $520 \mathrm{~mm}$. Rainfall was seasonal misdistribution, and concentrated from June to September and less in winter. The terrain of the pilot area is high in the southeast, low in the northwest and southwest, and the surface is flat. According to the rainwater pipe network plan, the study area can be divided into six drainage partitions.

\section{Establishing the Study Area Model}

The SWMM, which was developed by the US environmental protection agency (USEPA), is a dynamic rainfall-runoff simulation model. It is used to simulate single or continuous events of runoff quantity and quality in primarily urban areas. The SWMM is a hydrodynamic model of rainfall runoff, including hydrological, hydraulic, and water quality modules [17]. It can simulate the water quantity and quality of the runoff generated at different time steps and at any time in each sub-catchment. Moreover, the flow, water depth and water quality of each conduit can be simulated. The pollutant accumulation and washout model in water quality module were used to simulate the growth, scour, transportation and treatment of pollutants in surface runoff. The mathematical models for calculating the infiltration variation process are the Horton formula, Green-Ampt formula, and SCS characteristic curve method and so on. Considering the high requirement of the Green-Ampt method for soil characteristic data and scale requirement of SCS characteristic curve method, Horton infiltration was selected for the soil infiltration mode in each subcatchment. The model provides three calculation methods for the movement of water in pipelines, such as steady flow, motion wave and dynamic wave. In the steady flow method, the runoff of a pipeline can be calculated by simple equations. The kinematic wave method is limited for the application of branch pipe network. The dynamic wave method can solve problems such as water depth of node and the movement of pressure flow in the pipe, which is more consistent with the situation of the study area [18]. The dynamic wave method was adopted in this paper. For modeling requirements, the land-use types of residential areas, industrial areas, commercial areas, public facilities, roads and greening areas were divided into three types (road, roof, and greenbelt). The proportion of road, roof, and greenbelt of each sub-catchment were determined according to the nature of the study area. When the LID mode was simulated in the study 


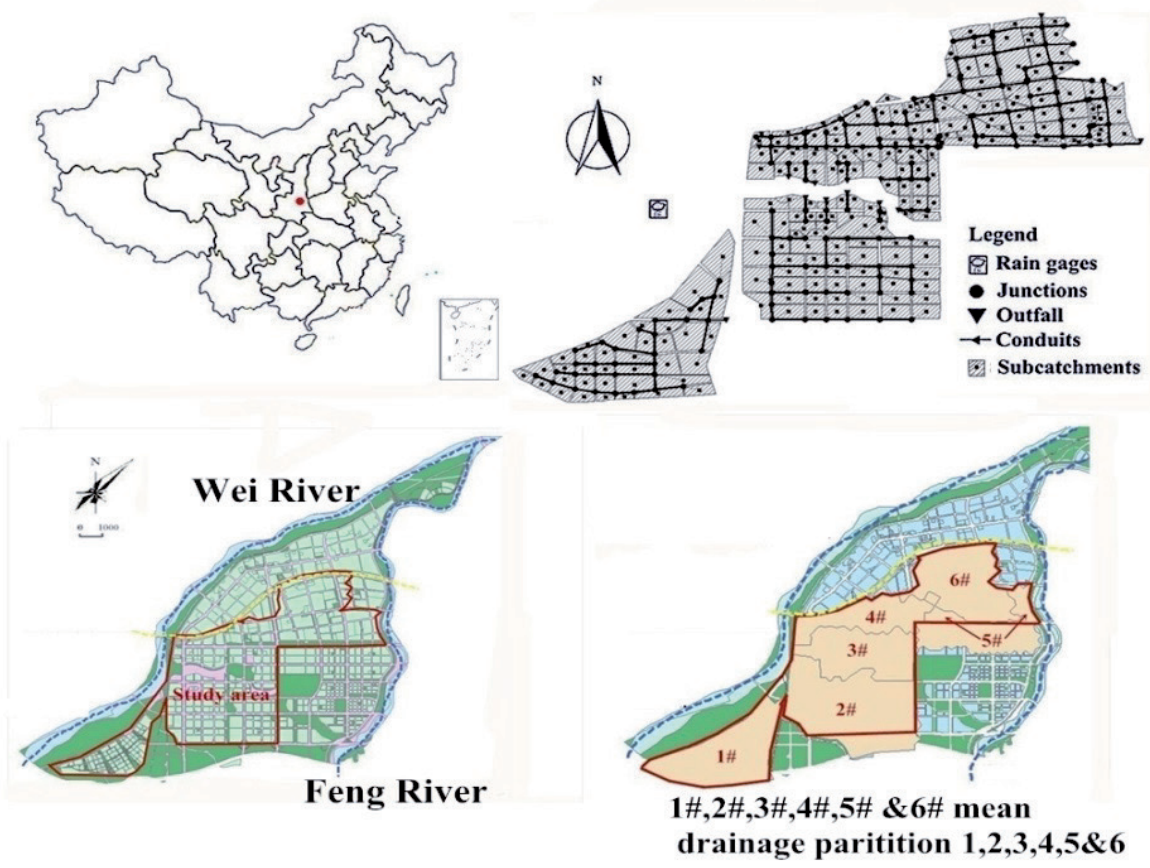

Fig. 1. Generalized map of study area.

Note: The red dot in the top-left graph shows the location of the study area.

area, the soil infiltration capacity of the study area could be fully utilized, and the impermeable area of development area could be reduced as much as possible for keeping the study area in its original state of natural hydrology. The location, area and parameters of LID facilities were determined from the LID special plan of the study area. Six types of LID facilities, including rain garden, infiltration trench, green roof, permeable pavement, rain barrels, and low-elevation greenbelt were selected.

According to the trend of the rainwater pipe network and distribution of buildings, the study area was divided into many sub-catchments. The generalization results are shown in Fig. 1 and the generalization results of drainage partition in the study area are presented in Table 1. The area proportions of different LID facilities are shown in Table 1. Each sub-catchment was equipped with five types of LID measures, including rain garden, infiltration trench, permeable pavement, rain barrels, and low-elevation greenbelt. A green roof was set in 184 sub-catchments.

\section{Rainfall Condition Design}

The rainstorm intensity equation in the study area is:

$$
\mathrm{q}=\begin{gathered}
2785.833(1+1.1658 \lg \mathrm{P}) \\
(\mathrm{t}+16.813)^{0.9302}
\end{gathered}
$$

...where $q$ is rainfall intensity, $\mathrm{L} /(\mathrm{s} \cdot \mathrm{ha}) ; P$ is the design recurrence period, a; and $t$ is the duration (minutes) of the rainfall events.

Table 1. Generalization results of study area and area proportions of LID facilities.

\begin{tabular}{|c|c|c|c|c|c|c|c|}
\hline Items & $1 \#$ & $2 \#$ & $3 \#$ & $4 \#$ & $5 \#$ & $6 \#$ & Total \\
\hline Sub-catchment/ind & 37 & 45 & 37 & 39 & 14 & 45 & 217 \\
\hline Node/ind & 31 & 31 & 18 & 32 & 14 & 39 & 165 \\
\hline Outlet/ind & 1 & 1 & 9 & 1 & 1 & 1 & 14 \\
\hline Conduits/ind & 31 & 31 & 18 & 32 & 14 & 39 & 165 \\
\hline Total area/ha & 530.7 & 629.7 & 298.9 & 296.4 & 123.3 & 485.9 & 2364.9 \\
\hline Items & Rain garden & $\begin{array}{c}\text { Infiltration } \\
\text { galleries }\end{array}$ & $\begin{array}{c}\text { Low-elevation } \\
\text { greenbelt }\end{array}$ & Rain barrel & Green roof & $\begin{array}{c}\text { Permeable } \\
\text { pavement }\end{array}$ & Total \\
\hline Area/ha & 76.09 & 75.23 & 75.71 & 76.3 & 42.07 & 111.09 & 456.5 \\
\hline Proportion/\% & 3.2 & 3.2 & 3.2 & 3.2 & 1.8 & 4.7 & 19.3 \\
\hline
\end{tabular}


The rainfall pattern of urban drainage design is divided into uniform and non-uniform rainfall patterns. The uniform pattern is the most widely used and simplest method, but the calculation results are less than actual rainfall. Chu and Keifer [19] had proposed a new type of inhomogeneous rainfall type, known as the Chicago rainfall pattern, to study the intensity-diachronicfrequency relationship. By comparing and analyzing the design of the rainstorm type that is commonly used domestically and overseas, Cen and Shen [20] found that unimodal rainfall type was the main type in short-duration rainfall events, and the rain peaks were mostly in the front and middle. The Chicago rainfall pattern can meet the precision requirements, and it has obtained good application in many cities because of its good adaptation effect. The Chicago rainfall pattern was selected to design rainfall process in the study area. The rainfall amount for the recurrence interval of 1,2 and 5 years with short duration $(3 \mathrm{~h})$, and for the recurrence interval of 10,20 , and 50 years with long duration $(24 \mathrm{~h})$ were calculated. The time step was 1 minute. The rainfall peak coefficient was 0.4 , which is an experience value due to the lack of local rainfall statistics. Based on the practical experience of developed countries, the optimal annual runoff reduction rate is $80-85 \%$. Factors such as rainfall characteristics, soil properties and building density were considered comprehensively to determine that the optimal annual runoff reduction rate is $85 \%$ in the study area. The typical rainfall process of $19.2 \mathrm{~mm}$ corresponding to $85 \%$ was designed, which lasts for $3 \mathrm{~h}$. The rainfall process in the study area is shown in Fig. 2. Rainfall events consisted of 0.5-, 1-, 2-, 5-, 10-, 20- and 50-year recurrence periods, which were expressed as $0.5 \mathrm{a}, 1 \mathrm{a}$, 2a,5a, 10a, 20a and 50a in tables and figures.

\section{Model Parameters}

The hydrological and hydraulic parameters mainly consist of the characteristic width of the catchment area, Manning coefficient, subsidence depth, and infiltration rates. The water quality parameters include scouring index and erosion coefficient in the scouring model, as well as maximum cumulative and cumulative rate constants in accumulation function. The parameters of pipe length and diameter, node elevation, surface area, and ratio of the impermeable area were obtained from the rainwater plan of the study area. The rest of the parameters were determined preliminarily by the actual situation of the study area, the SWMM user's manual [21] and related literature [6].

\section{Sensitivity Analysis}

For studying the urban rainfall runoff pollution model, the sensitivity analysis of parameters is necessary in the process of model calibration and validation, which qualitatively or quantitatively evaluates the effect of the model input error on the model output.
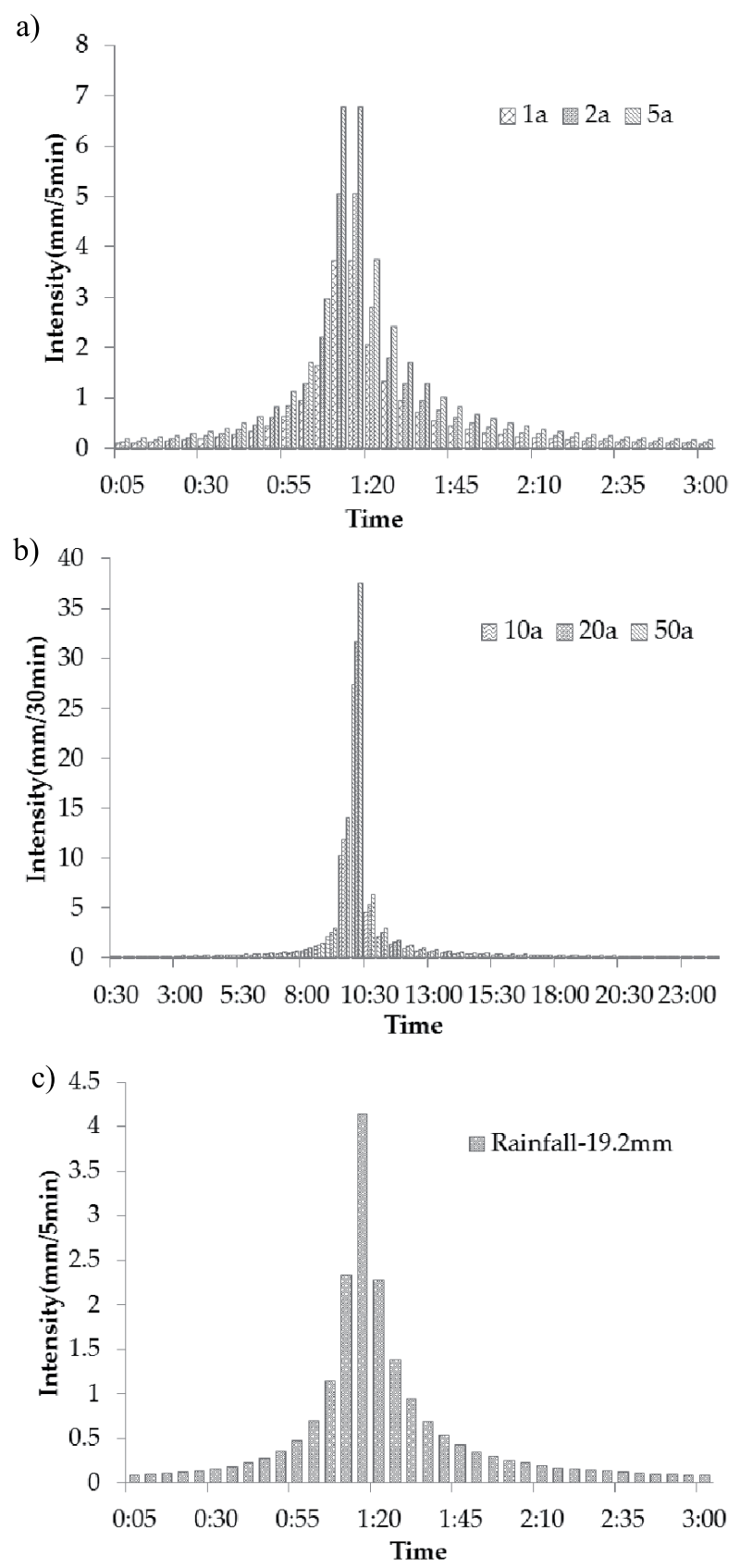

Fig. 2. Rainfall process of different design rainfall events: a) Design rainfall of short duration, b) Design rainfall of long duration, c) Design rainfall of $19.2 \mathrm{~mm}$ rainfall.

According to the sensitivity analysis, the efficiency of parameter identification and model validation will be improved. The parameter sensitivity was analyzed using the Morris screening method under traditional development (TD) mode. On the basis of the Morris screening method, a parameter is taken as a variable $x_{i}$, and the rest of the parameters are kept invariant. The variable $x_{i}$ is randomly changed within the value range of the variable and the result of the objective function $y\left(x_{\mathrm{i}}\right)$ corresponding to different $x_{i}$ obtained by running the model. The influence value $e_{i}$ is used to indicate the influence degree of the parameter variation on the model simulation results [22-23]. 


$$
e_{i}=\left(y-y_{0}\right) / \Delta_{i}
$$

...where $e_{i}$ is the Morris coefficient, $y$ is the model output values after the parameters changed, $y_{0}$ is the model output values before the parameters changed, and $\Delta_{i}$ is the amplitude of parameter $i$.

The Morris screening method makes independent variables change with a fixed step size percentage. Finally, sensitivity discriminant factor is the average of multiple Morris coefficients. The equation is:

$$
\mathrm{SN}=\sum_{\mathrm{i}=1}^{\mathrm{n}} \frac{\left(\mathrm{Y}_{\mathrm{i}+1}-\mathrm{Y}_{\mathrm{i}}\right) / \mathrm{Y}_{0}}{\left(\mathrm{P}_{\mathrm{i}+1}-\mathrm{P}_{\mathrm{i}}\right) / 100} / \mathrm{n}
$$

...where $\mathrm{SN}$ is the sensitivity discriminant factor, $Y_{i}$ is the output value of the $i$ th running of the model, $Y_{i+1}$ is the output value of the $(i+1)$ th running, $Y_{0}$ is the initial value of the calculation result after the parameter adjustment, $P_{i}$ is the percentage change of the parameter values after the $i$ th simulation relative to the initial parameter values, $P_{i+1}$ is the percentage change of the parameter values after the $(i+1)$ th simulation relative to the initial parameter values, and $n$ is the running times. The sensitivity of parameters is divided into four categories, named the parameters of $|\mathrm{SN}| \geq 1$, which are the highly sensitive parameters; the parameters of $0.2 \leq|\mathrm{SN}|<1$, which are the sensitive parameters; the parameters of $0.05 \leq|\mathrm{SN}|<0.2$, which are the mid-sensitive parameters; and the parameters of $0 \leq|\mathrm{SN}|<0.05$, which are the insensitive parameters.

A total of 10 main parameters need to be calibrated in the hydrological and hydraulic module, including the characteristic width and slope of the sub-catchments, Manning coefficient and water-storage depth of permeable and impermeable areas, pipe Manning coefficient, maximum and minimum infiltration rates, and infiltration decay constant. The pollution accumulation and washout parameters under different land uses should be calibrated. The parameters were perturbed by using a fixed-step of $5 \%$. That is, when other parameters are kept invariant, the values of one parameter are taken from the initial value of $-20 \%$, $-15 \%,-10 \%,-5 \%,+5 \%,+10 \%,+15 \%$ and $+20 \%$ to calculate the fluctuation degree of the simulation results. The rainfall events of $19.2 \mathrm{~mm}, 2$-year and 20 -year recurrence periods under TD mode were used for analysis. Parameter sensitivity related to total runoff, peak flow, and SS were analyzed. Figs 3 and 4 show the results.

According to the sensitivity classification of Morris screening, they were not highly sensitive in the 22 parameters. The average SN values of 10 hydrological hydraulic module parameters on total runoff amount were $0.09,0.07,0.02,0.06,0.03,0,0.03,0.08,0.03$ and 0.04 . The average SN values of 10 hydrological hydraulic module parameters on peak flow were 0.17 , $0.05,0.12,0.03,0.04,0.73,0.02,0.02,0.01$ and 0.08 . The average SN values of 12 water quality parameters on SS were $0.32,-0.20,0.05,0,0.18,-0.09,0.02,0$,
$0.06,-0.18,0.12$ and 0.01 . The results showed that: (1) For the sensitivities of parameters on total runoff amount, the mid-sensitive parameters were the width of the catchment area, the minimum infiltration rate, the manning coefficient and the water-storage depth of the permeable area. Their sensitivities successively

a)
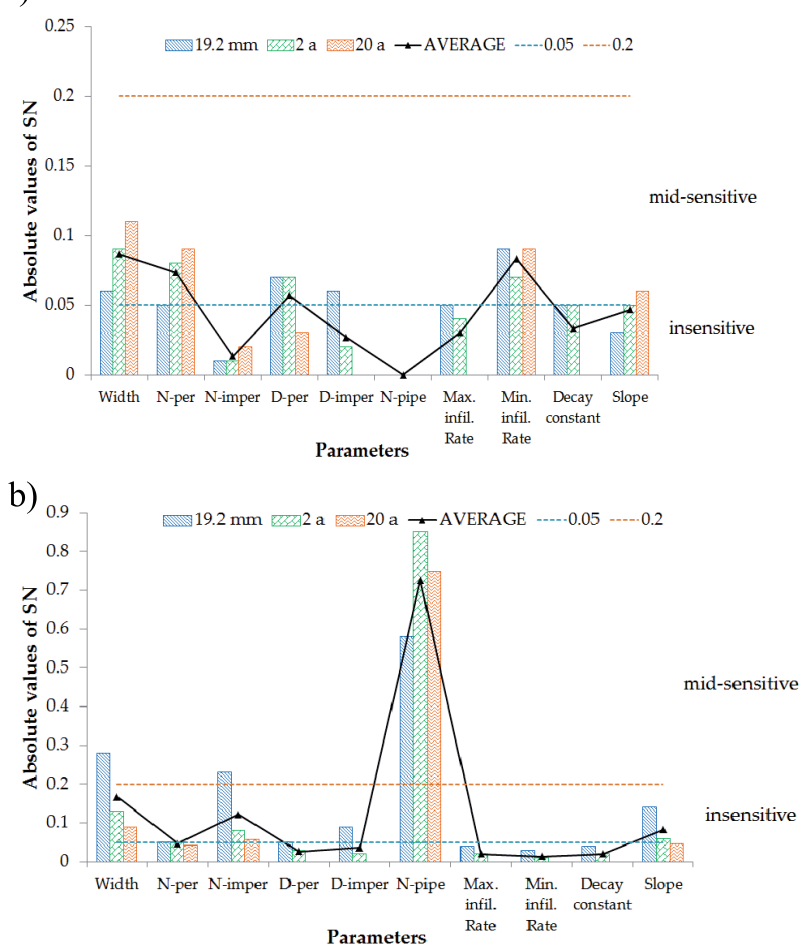

Fig. 3. Absolute values of sensitivity for hydrological hydraulic module parameters: a) Sensitivity of parameters on runoff, b) Sensitivity of parameters on flow peak.

Note: N-per/N-imper is the manning coefficient of permeable/ impermeable area; D-per/D-imper is the water-storage depth in permeable/ impermeable area; Max. infil. Rate is the maximum infiltration rate; Min. infil. Rate is the minimum infiltration rate. N-pipe is pipe manning coefficient. Variable coefficient is the discrete degree of sensitivity values.

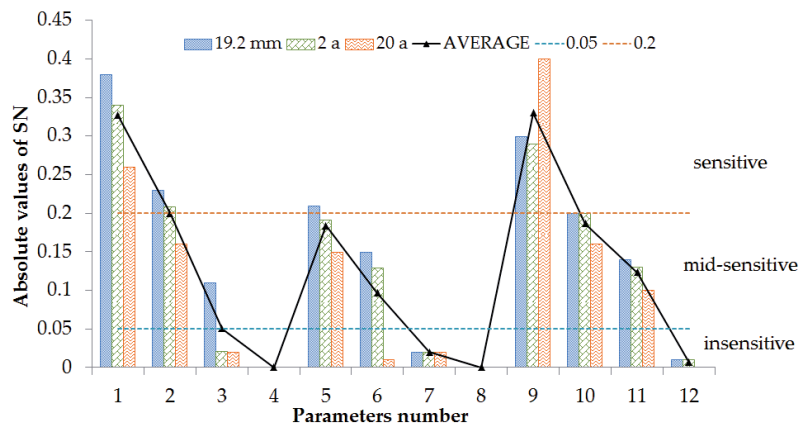

Fig. 4. Absolute values of sensitivity for hydrological hydraulic module parameters. Note: 1 is Road max buildup; 2 is Road rate constant; 3 is Road coefficient; 4 is Road exponent; 5 is Roof max buildup; 6 is Roof rate constant; 7 is Roof coefficient; 8 is Roof exponent; 9 is Greenbelt max buildup; 10 is Greenbelt rate constant; 11 is Greenbelt coefficient; 12 is Greenbelt exponent. 
Table 2. Final values of model parameters.

\begin{tabular}{|c|c|c|c|c|c|c|c|}
\hline Parameters & Value & Parameters & Land use & SS & COD & ТP & $\mathrm{TN}$ \\
\hline \multirow{2}{*}{ N-Imper } & \multirow{2}{*}{0.013} & \multirow{3}{*}{$\begin{array}{l}\text { Max. accumulation } \\
(\mathrm{Kg} / \mathrm{ha})\end{array}$} & Roof & 140 & 100 & 1.4 & 2.3 \\
\hline & & & Greenbelt & 120 & 120 & 1 & 19 \\
\hline N-per & 0.14 & & Road & 130 & 90 & 1.5 & 27 \\
\hline $\begin{array}{l}\text { D-Imper } \\
(\mathrm{mm})\end{array}$ & 2.06 & \multirow{3}{*}{$\begin{array}{l}\text { Half-saturation } \\
\qquad(1 / d)\end{array}$} & Roof & 10 & 10 & 10 & 10 \\
\hline D-per (mm) & 3.78 & & Greenbelt & 10 & 10 & 10 & 10 \\
\hline $\begin{array}{l}\text { Max.infil.rate } \\
(\mathrm{mm} / \mathrm{h})\end{array}$ & 25.4 & & Road & 8 & 8 & 6 & 8 \\
\hline \multirow{2}{*}{$\begin{array}{l}\text { Min.infil.rate } \\
\quad(\mathrm{mm} / \mathrm{h})\end{array}$} & \multirow{2}{*}{3.37} & \multirow{3}{*}{ Exponent } & Roof & 0.4 & 0.54 & 0.45 & 0.55 \\
\hline & & & Greenbelt & 0.2 & 0.53 & 0.5 & 0.53 \\
\hline $\begin{array}{l}\text { Decay constant } \\
(1 / \mathrm{d})\end{array}$ & 7 & & Road & 0.5 & 0.8 & 0.45 & 0.45 \\
\hline \multirow{3}{*}{ Roughness } & \multirow{3}{*}{0.013} & \multirow{3}{*}{ Coefficient } & Roof & 0.009 & 0.008 & 0.008 & 0.008 \\
\hline & & & Greenbelt & 0.09 & 0.085 & 0.09 & 0.085 \\
\hline & & & Road & 0.008 & 0.007 & 0.007 & 0.007 \\
\hline Layer & Parameters & Rain garden & $\begin{array}{l}\text { Infiltration } \\
\text { galleries }\end{array}$ & $\begin{array}{c}\text { Low-elevation } \\
\text { greenbelt }\end{array}$ & $\begin{array}{l}\text { Rain } \\
\text { barrels }\end{array}$ & $\begin{array}{l}\text { Green } \\
\text { roof }\end{array}$ & $\begin{array}{l}\text { Permeable } \\
\text { pavement }\end{array}$ \\
\hline \multirow{3}{*}{ Surface } & $\begin{array}{l}\text { Height } \\
(\mathrm{mm})\end{array}$ & 300 & 20 & 200 & 900 & 100 & 100 \\
\hline & Roughness & 0.15 & 0.13 & 0.1 & - & 0.1 & 0.2 \\
\hline & Slope & 0.1 & 0.1 & 1 & - & 1 & 1.5 \\
\hline \multirow{3}{*}{ Soil } & $\begin{array}{l}\text { Thickness } \\
(\mathrm{mm})\end{array}$ & 800 & - & 300 & - & 150 & - \\
\hline & Porosity & 0.5 & - & 0.5 & - & 0.4 & - \\
\hline & $\begin{array}{l}\text { Condutivity } \\
(\mathrm{mm} / \mathrm{h})\end{array}$ & 100 & - & 100 & - & 100 & - \\
\hline \multirow{3}{*}{ Storage } & Height (mm) & 500 & 400 & - & - & 150 & 400 \\
\hline & Void ratio & 0.75 & 0.75 & - & - & 0.75 & 0.75 \\
\hline & $\begin{array}{c}\text { Condutivity } \\
(\mathrm{mm} / \mathrm{h})\end{array}$ & 15 & 25 & - & - & - & 250 \\
\hline \multirow{2}{*}{ Drain } & Coefficient & 0.1 & 0.1 & - & - & - & 0.1 \\
\hline & Exponent & 0.5 & 0.5 & - & - & - & 0.5 \\
\hline
\end{tabular}

decreased. The SN value dispersion degree of the waterstorage depth of the permeable area is the maximum, and which of the minimum infiltration rate is the maximum. (2) For peak flow, pipe manning coefficient was the sensitivity parameter. The mid-sensitive parameters were three, including the width of the subcatchment, the manning coefficient of a permeable area, and the slope of the sub-catchments, the sensitivity of which decreased successively. These results are similar to the findings of Shi et al. [24]. (3) Seven parameters were sensitive to SS. The sensitivity parameters included the maximum accumulation and the halfsaturated constant of the road. The moderate sensitivity parameters included the maximum accumulation of roof and greenbelt, the half-saturated constant of the roof and greenbelt, and the scouring coefficient of the greenbelt. The research results reported by $\mathrm{Li}$ et al. [25] also showed that the accumulation parameters of the road and roof are sensitive parameters.

\section{Calibration and Validation}

The study area is a newly-built area where the pipe network system was not completely built. Without the measured rainfall data on water quantity and quality, the calibration and verification of the model parameters cannot be conducted through the measured data of the outlets. Therefore, the initial parameter values were determined by referring to a study on the same basin [6]. From the results of parameter sensitivity analysis, 
model parameters were manually debugged, and a runoff coefficient was calculated by simulation results. The model parameters were determined when the runoff coefficient obtained by simulation was close to the empirical value of comprehensive runoff coefficient obtained from Code for design of outdoor wastewater engineering (GB50014-2006, China).

The design rainfall events of 2- and 5-year recurrence periods were adopted to verify the model stability under different rainfall conditions. The simulated runoff coefficients of two rainfall events were 0.523 and 0.597 , which meet the requirements of the comprehensive runoff coefficient $(0.5-0.7)$ in residential areas with dense buildings [26-27]. Comparing the rainfall and flood peak flow at each outlet under 2- and 5-year recurrence periods, it was found that the peak flow increased with the increase of rainfall amount, which confirmed to the runoff production and flow collection pattern. After verification, the model parameters had good applicability and could be used for regional simulation. Table 2 shows the final values of the model parameters of three modules and the parameters of each single LID facility, which were determined by the Special plan report on low-impact development of the study area.

\section{Exploration for the Correlation between Reductions of NPS Load and Rainfall Runoff}

From the formation process of rainfall-runoff pollution, only when runoff is formed, runoff pollution could possibly produce in a rainfall process. Runoff pollution load is closely related to rainfall runoff. In the same way, the reduction amount of NPS pollution load is based on the reduction amount of runoff. The reduction amounts of NPS load and rainfall runoff were calculated and analyzed for exploring and establishing the relationship of NPS pollution load reduction amount and runoff reduction amount. In this paper, the effects of LID combined facilities on hydrological and environmental effect in the study area were evaluated from the aspects of overflow nodes, reduction of water quantity and quality, and concentration removal. The relationship between runoff reduction amount and the reduction amounts of major pollutants such as $\mathrm{SS}, \mathrm{COD}$, $\mathrm{TP}$ and TN were explored and established. It could provide reference for the construction of sponge city and the reasonable plan of LID. The main structure is shown in Fig. 5.

\section{Results and Analyses}

\section{Hydrological and Environmental Effects under Different Design Rainfall Scenarios}

Waterlogging occurred at low-lying places and was formed while pipe displacement exceeds the upper limit of capacity. The overflow nodes were evaluated based on overload time and the time and value of the maximum flow. The analysis of runoff was mainly evaluated based on runoff reduction rates. The total pollution load reduction rates of SS, chemical oxygen demand (COD), total phosphorus (TP) and total nitrogen (TN) were calculated.

\section{Simulation Analysis of Overflow Nodes}

After the sorting and analysis of the rainfall under different design rainfall events, the overload time of the nodes mainly centered on 1:25-1:50 for the $3 \mathrm{~h}$ rainfall, which centered on 9:38-10:05 for the $24 \mathrm{~h}$ rainfall. The results of the overflow nodes are shown in Table 3 .

Under TD and LID modes, there were few overflow nodes in short duration $(3 \mathrm{~h})$ rainfall events. No overflow node under rainfall of 0.5-year recurrence period was observed. Under TD mode, the number of overflow nodes was reduced from 61 to 7 under rainfall of 5-year recurrence period, whereas the remaining overflow nodes were 0 . For the long duration rainfall events $(24 \mathrm{~h})$, the number of overflow nodes increased gradually. In sponge city assessment, the time of

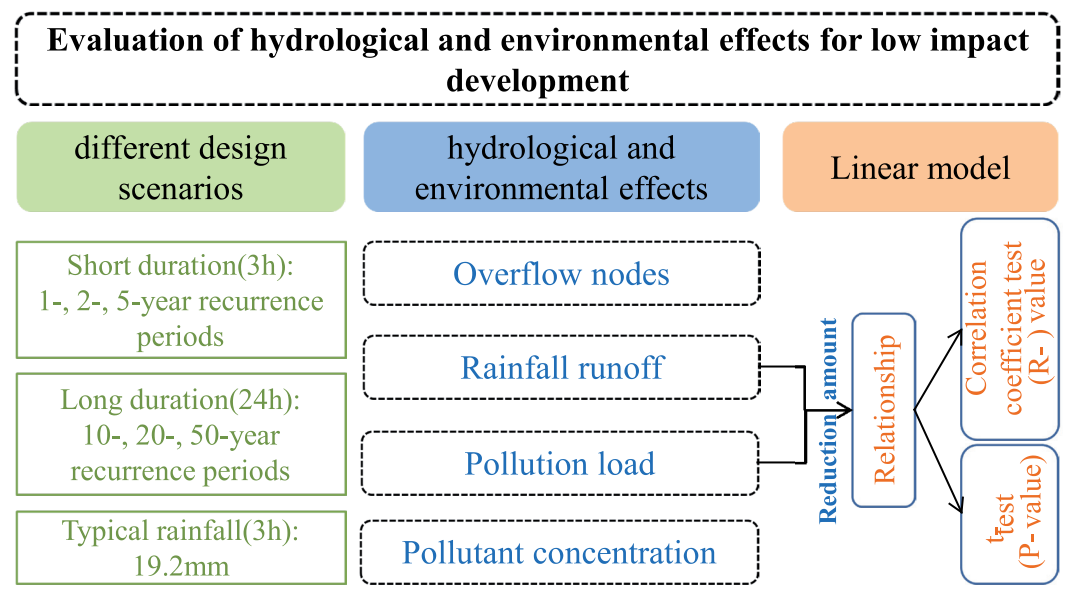

Fig. 5. Study framework and contents. 
Table 3. Statistical results of overflow nodes.

\begin{tabular}{|c|c|c|c|c|c|c|c|}
\hline \multirow{2}{*}{ Rain events } & \multirow{2}{*}{$\begin{array}{l}\text { Rainfall } \\
\text { duration }\end{array}$} & \multicolumn{2}{|c|}{ Number of overflow nodes } & \multicolumn{2}{|c|}{ Maximum flow rate $\left(\mathrm{m}^{3} / \mathrm{s}\right)$} & \multicolumn{2}{|c|}{ Duration range $(\mathrm{h})$} \\
\hline & & $\mathrm{TD}$ & LID & $\mathrm{TD}$ & LID & $\mathrm{TD}$ & LID \\
\hline $0.5 \mathrm{a}$ & $3 \mathrm{~h}$ & 0 & 0 & - & - & - & - \\
\hline $19.2 \mathrm{~mm}$ & & 3 & 0 & 0.595 & - & $0.53 \sim 0.96$ & - \\
\hline $1 \mathrm{a}$ & & 5 & 0 & 0.838 & - & $0.08 \sim 1.24$ & - \\
\hline $2 \mathrm{a}$ & & 21 & 0 & 2.045 & - & $0.22 \sim 1.81$ & - \\
\hline $5 \mathrm{a}$ & & 61 & 7 & 4.375 & 2.807 & $0.01 \sim 2.27$ & $0.07 \sim 1.02$ \\
\hline $10 \mathrm{a}$ & $24 \mathrm{~h}$ & 92 & 22 & 8.680 & 2.876 & $0.01 \sim 3.07$ & $0.06 \sim 2.21$ \\
\hline $20 \mathrm{a}$ & & 104 & 41 & 12.249 & 3.835 & $0.01 \sim 3.45$ & $0.01 \sim 2.67$ \\
\hline $50 \mathrm{a}$ & & 116 & 75 & 15.500 & 4.407 & $0.01 \sim 3.49$ & $0.01 \sim 3.16$ \\
\hline
\end{tabular}

Note: TD: Traditional development mode; LID: Low impact development mode.

waterlogging is required to be less than $30 \mathrm{~min}$, and the depth of waterlogging is required to be $15 \mathrm{~cm}$ under a 50-year recurrence period. Under TD mode, 70 overflow nodes were waterlogged more than $30 \mathrm{~min}$, the number of which was reduced by 31 under the LID mode. Overflow nodes mainly concentrated in the $2 \#$, $4 \#$, and $6 \#$ partitions because $2 \#$ and $4 \#$ partitions were mainly industrial and commercial areas which have the great harden surface and poor permeability, resulting in the load increase of runoff and nodes. The setting of many facilities was restricted in the calculation of LID mode, which cannot achieve the optimal low-impact development because $6 \#$ partitioning is an old urban area.

The number of overflow nodes, the maximum flow rates and overload time increased gradually with the increase of rainfall recurrence periods. At the same time, the number of overflow nodes under LID mode decreased. The same conclusion on the study of different rainfall recurrence periods was drawn from $\mathrm{Fu}$ et al. [18]. In different rainfall events, the phenomenon of waterlogging under LID mode had a weakening effect compared with TD mode. LID combined facilities had a good effect on the remission of overflow nodes. Rainfall in the non-rainstorm intensity can achieve the full removal of overflow. Moreover, LID combined facilities had a certain control effect for the heavy rainfall process.

\section{Simulation Analysis of Total Runoff}

The reduction rates of runoff under different recurrence periods were obtained under different modes. Table 4 shows the results.

LID combined facilities had a good effect on the control of short duration $(3 \mathrm{~h})$ rainfall events. The runoff reduction rates at rainfall events of $0.5-, 1-, 2-$ and 5 -year recurrence periods and rainfall of $19.2 \mathrm{~mm}$ had reached above $44 \%$. At the rainfall events of $0.5-, 1-$, 2- and 5-year recurrence periods, the runoff reduction rates under LID mode were improved by $33.3 \%, 36.3 \%$, $35.9 \%$ and $24.7 \%$ respectively compared to TD mode. For long-duration (24 h) rainfall events with 10-, 20- and 50 -year recurrence periods, the runoff reduction rates were improved by $22.3 \%, 20.2 \%$ and $18.3 \%$ respectively under LID mode compared to TD mode. For the

Table 4. Results for water quantity in study area under TD and LID modes.

\begin{tabular}{|c|c|c|c|c|c|c|c|c|}
\hline $\begin{array}{c}\text { Rain } \\
\text { events }\end{array}$ & $\begin{array}{c}\text { Duration of } \\
\text { rainfall }\end{array}$ & Area (ha) & $\begin{array}{c}\text { Rainfall } \\
(\mathrm{mm})\end{array}$ & $\begin{array}{c}\text { Total inflow } \\
\left(\mathrm{m}^{3}\right)\end{array}$ & $\begin{array}{c}\text { Total drainage } \\
\text { of TD }\left(\mathrm{m}^{3}\right)\end{array}$ & $\begin{array}{c}\text { Total drainage } \\
\text { of LID }\left(\mathrm{m}^{3}\right)\end{array}$ & $\begin{array}{c}\text { Reduction } \\
\text { rates of TD }\end{array}$ & $\begin{array}{c}\text { Reduction } \\
\text { rates of LID }\end{array}$ \\
\hline $0.5 \mathrm{a}$ & $3 \mathrm{~h}$ & 2364.91 & 14.37 & 339838 & 158246 & 45014 & $53.4 \%$ & $86.8 \%$ \\
\hline $19.2 \mathrm{~mm}$ & & 2364.91 & 19.20 & 454063 & 231957 & 67016 & $48.9 \%$ & $85.2 \%$ \\
\hline $1 \mathrm{a}$ & & 2364.91 & 22.14 & 523591 & 278016 & 90072 & $46.9 \%$ & $82.8 \%$ \\
\hline $2 \mathrm{a}$ & & 2364.91 & 29.92 & 707581 & 395598 & 169256 & $44.1 \%$ & $76 . \%$ \\
\hline $5 \mathrm{a}$ & & 2364.91 & 40.19 & 950457 & 519452 & 284295 & $45.4 \%$ & $70.1 \%$ \\
\hline $10 \mathrm{a}$ & $24 \mathrm{~h}$ & 2364.91 & 59.86 & 1415635 & 755656 & 440669 & $46.6 \%$ & $68.9 \%$ \\
\hline $20 \mathrm{a}$ & & 2364.91 & 69.24 & 1637464 & 854408 & 524333 & $47.8 \%$ & $68.0 \%$ \\
\hline $50 \mathrm{a}$ & & 2364.91 & 82.00 & 1939226 & 974627 & 620744 & $49.7 \%$ & $68.0 \%$ \\
\hline
\end{tabular}

Note: TD: Traditional development mode; LID: Low-impact development mode. 
Table 5. Pollution loads under different modes.

\begin{tabular}{|c|c|c|c|c|c|c|}
\hline \multirow{2}{*}{ Duration } & \multirow{2}{*}{\multicolumn{2}{|c|}{ Rainfall events }} & \multicolumn{4}{|c|}{ Quantity of pollutant discharged (kg) } \\
\hline & & & SS & COD & ТP & $\mathrm{TN}$ \\
\hline \multirow{8}{*}{$3 \mathrm{~h}$} & \multirow{2}{*}{$0.5 \mathrm{a}$} & TD & 7744 & 10538 & 199 & 2658 \\
\hline & & LID & 1393 & 1909 & 39 & 526 \\
\hline & \multirow{2}{*}{$19.2 \mathrm{~mm}$} & $\mathrm{TD}$ & 9854 & 13239 & 270 & 3433 \\
\hline & & LID & 2303 & 3125 & 68 & 870 \\
\hline & \multirow{2}{*}{$1 \mathrm{a}$} & TD & 11631 & 14803 & 313 & 3895 \\
\hline & & LID & 3121 & 4080 & 91 & 1141 \\
\hline & \multirow{2}{*}{$2 \mathrm{a}$} & TD & 16146 & 18319 & 420 & 4990 \\
\hline & & LID & 5911 & 6853 & 162 & 1953 \\
\hline \multirow{8}{*}{$24 \mathrm{~h}$} & \multirow{2}{*}{$5 \mathrm{a}$} & TD & 21003 & 21333 & 529 & 6020 \\
\hline & & LID & 9944 & 10358 & 267 & 3060 \\
\hline & \multirow{2}{*}{$10 \mathrm{a}$} & TD & 31919 & 29499 & 767 & 8615 \\
\hline & & LID & 14818 & 13913 & 399 & 4363 \\
\hline & \multirow{2}{*}{$20 \mathrm{a}$} & TD & 35949 & 30954 & 847 & 9286 \\
\hline & & LID & 17338 & 15309 & 467 & 4958 \\
\hline & \multirow{2}{*}{$50 \mathrm{a}$} & TD & 40876 & 32484 & 945 & 10067 \\
\hline & & LID & 20316 & 16618 & 544 & 5593 \\
\hline
\end{tabular}

Note: TD: Traditional development mode; LID: Low-impact development mode.

$19.2 \mathrm{~mm}$ rainfall, the runoff reduction rate was $48.9 \%$ under TD mode; the runoff reduction rate was $85.2 \%$ under LID mode. The regional overall plan target of sponge city construction with an annual total runoff reduction rate more than $85 \%$ can be met under LID mode.

There were 6 kinds of LID facilities for surface runoff simulation at different rainfall conditions in this study, including rain gardens, infiltration trench, green roof, permeable pavement, rain barrel and lowelevation greenbelt. Simulation results show that the total surface runoff reduction rate and the delay of flow peak appearance time were great. For low return period rainfall events, the delay time of flow peak was long. Total runoff and peak flow were simulated after the setting of low elevation greenbelt and permeable pavement based on SWMM by Wang et al. [28]. Wang's results were similar to this study that total surface runoff and peak flow were controlled effectively. The research of Pan et al. [29] also showed that total surface runoff could be cut down, and flow peak appearance time was delayed. Meanwhile, flow peak delay time by LID for short duration precipitation was long.

\section{Simulation Analysis of NPS Pollution Load}

Urban rainfall runoff contained a variety of pollutants, including $\mathrm{SS}, \mathrm{COD}, \mathrm{TP}, \mathrm{TN}$, biochemical oxygen demand, heavy metals and so on. The main sources of pollutants were atmospheric subsidence, vehicle traffic, plant growth, animal activity, building erosion and so on. The pollutants of different land uses were discharged into the receiving water by rainfall washout, which polluted water bodies at different degrees. The pollution load reduction rates under different development modes were simulated based on the indexes of the main pollutants in the study area, namely SS, COD, TP, and TN. Table 5 shows the results of the simulation.

Compared with TD mode, the amounts of pollution load were controlled under the LID mode. After adding LID combined facilities, the total amounts of SS decreased by $82.0 \%, 76.6 \%, 73.2 \%, 63.7 \%$ and $52.7 \%$ respectively; COD decreased by $81.9 \%, 76.4 \%, 72.4 \%$, $62.6 \%$ and $51.5 \%$ respectively; TP decreased by $80.3 \%$, $74.8 \%, 71.1 \%, 61.5 \%$ and $49.6 \%$ respectively; and TN decreased by $80.2 \%, 74.7 \%, 70.7 \%, 60.9 \%$ and $49.2 \%$ respectively under short duration rainfall events $(3 \mathrm{~h})$. Under long duration rainfall events, the total amounts of SS decreased by $53.6 \%, 51.8 \%$ and $50.3 \%$ respectively; COD decreased by $52.8 \%, 50.5 \%$ and $48.8 \%$ respectively; TP decreased by $47.9 \%, 44.9 \%$ and $42.4 \%$ respectively; TN decreased by $49.4 \%, 46.6 \%$ and $44.4 \%$ respectively. LID combined facilities had a marked effect on pollutant load and could improve the water quality of the runoff. The accumulation and washout degrees of pollutants were different so that the pollution load caused by the rainfall runoff was also different. Although the different 
Table 6. EMC values of runoff pollutants under different design rainfall events.

\begin{tabular}{|c|c|c|c|c|c|c|}
\hline \multirow{2}{*}{$\begin{array}{l}\text { Duration of } \\
\text { rainfall }\end{array}$} & \multirow{2}{*}{\multicolumn{2}{|c|}{ Rain events }} & \multicolumn{4}{|c|}{$\mathrm{EMC}(\mathrm{mg} / \mathrm{L})$} \\
\hline & & & SS & COD & TP & $\mathrm{TN}$ \\
\hline \multirow{15}{*}{$3 \mathrm{~h}$} & \multirow{3}{*}{$0.5 \mathrm{a}$} & TD & 48.94 & 66.59 & 1.26 & 16.80 \\
\hline & & LID & 30.94 & 42.41 & 0.87 & 11.69 \\
\hline & & Percentage & $36.8 \%$ & $36.3 \%$ & $30.7 \%$ & $30.4 \%$ \\
\hline & \multirow{3}{*}{$19.2 \mathrm{~mm}$} & TD & 42.48 & 57.08 & 1.16 & 14.80 \\
\hline & & LID & 34.36 & 46.63 & 1.02 & 12.99 \\
\hline & & Percentage & $19.1 \%$ & $18.3 \%$ & $12.8 \%$ & $12.3 \%$ \\
\hline & \multirow{3}{*}{$1 \mathrm{a}$} & TD & 41.84 & 53.24 & 1.13 & 14.01 \\
\hline & & LID & 34.65 & 45.30 & 1.01 & 12.66 \\
\hline & & Percentage & $17.2 \%$ & $14.9 \%$ & $10.6 \%$ & $9.6 \%$ \\
\hline & \multirow{3}{*}{$2 \mathrm{a}$} & TD & 40.82 & 46.31 & 1.06 & 12.61 \\
\hline & & LID & 34.92 & 40.49 & 0.96 & 11.54 \\
\hline & & Percentage & $14.4 \%$ & $12.6 \%$ & $9.9 \%$ & $8.5 \%$ \\
\hline & \multirow{3}{*}{$5 a$} & TD & 40.43 & 41.07 & 1.02 & 11.59 \\
\hline & & LID & 34.98 & 36.43 & 0.94 & 10.76 \\
\hline & & Percentage & $13.5 \%$ & $11.3 \%$ & $7.9 \%$ & $7.1 \%$ \\
\hline \multirow{9}{*}{$24 \mathrm{~h}$} & \multirow{3}{*}{$10 \mathrm{a}$} & $\mathrm{TD}$ & 42.24 & 39.04 & 1.01 & 11.40 \\
\hline & & LID & 33.63 & 31.57 & 0.91 & 9.90 \\
\hline & & Percentage & $20.4 \%$ & $19.1 \%$ & $10.7 \%$ & $13.2 \%$ \\
\hline & \multirow{3}{*}{$20 \mathrm{a}$} & TD & 42.08 & 36.23 & 0.99 & 10.87 \\
\hline & & LID & 33.07 & 29.20 & 0.89 & 9.45 \\
\hline & & Percentage & $21.4 \%$ & $19.4 \%$ & $10.2 \%$ & $13.0 \%$ \\
\hline & \multirow{3}{*}{$50 \mathrm{a}$} & TD & 41.94 & 33.33 & 0.97 & 10.33 \\
\hline & & LID & 32.73 & 26.77 & 0.88 & 9.01 \\
\hline & & Percentage & $22.0 \%$ & $19.7 \%$ & $9.6 \%$ & $12.8 \%$ \\
\hline
\end{tabular}

Note: TD: Traditional development mode; LID: Low-impact development mode; Percentage: the reduction rate of effluent concentration under LID mode compared with TD mode.

pollution loads had various effects, the changing curves of pollutant concentration had a certain similarity. Total discharge amount of pollutants was positively correlated with the rainfall recurrence periods. With the increasing rainfall recurrence periods, rainfall amount increased, and the washout degree of runoff became larger, which made the rainfall runoff pollution load larger. When the rainfall duration maintained invariability, the reduction rates of each pollution load were negatively correlated with the recurrence periods.

\section{Simulation Analysis of Pollutant Concentration in Different Recurrence Periods}

The outlet of $6 \#$ partition was taken as an example. The average concentration of runoff pollutants under different design rainfall events is shown in Table 6. The change process of pollutant concentration under 5- and 50-year recurrence periods are shown in Fig. 6.

As Table 6 shows, compared with TD mode, the average effluent concentrations of SS, COD, TP and TN under LID mode were reduced by $13.5-36.8 \%$, $11.3-36.3 \%, 7.9-30.7 \%$, and $7.1-30.4 \%$ respectively in short-duration rainfall events. Under long-duration rainfall events, the average effluent concentrations of SS, COD, TP and TN under LID mode were reduced by $20.4-22.0 \%, 19.1-19.7 \%, 9.6-10.7 \%$, and $12.8-13.2 \%$ respectively. With the recurrence periods increased, the pollutant concentrations of the four indexes gradually decreased. The effluent pollutant concentration was efficiently removed after adding LID combined facilities. 
a)

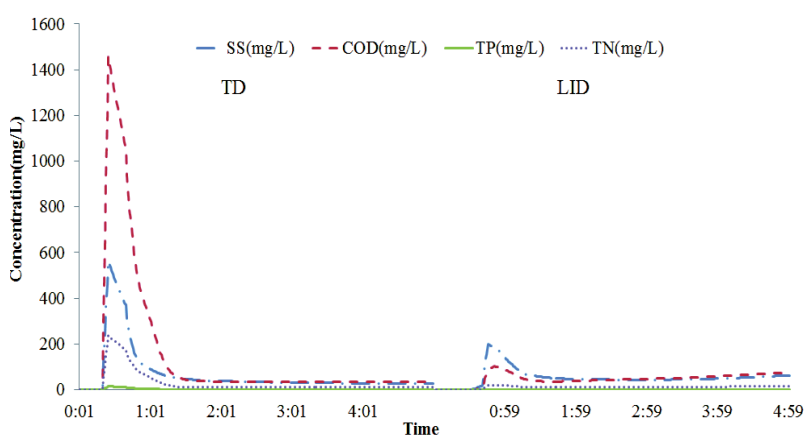

b)

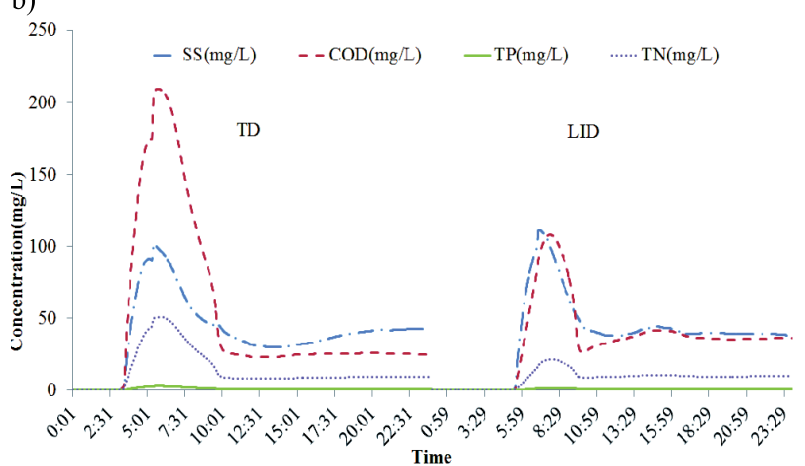

Fig. 6. Change process of pollutant concentrations (take 6\# outlet, for example): a) 5-year recurrence period, b) 50-year recurrence period.

The pollutant concentrations of runoff rapidly increased and soon reached the peak values at the initial rainfall. As the rainfall continued, the pollutant concentration gradually decreased and tended to stabilize. Comparing the concentrations under TD and LID modes, the pollutant peak concentrations were reduced while the appearance time of peak concentrations were obviously delayed. The LID combined facilities had a great effect on pollutant concentration of runoff, and the change process of pollutant concentration had a certain similarity. The process curves of pollutant concentrations changed during the 50-year recurrence period for $6 \#$ partition, revealing that the concentration still increased to a small peak after rainfall. Due to the different conflux times of the overland flow produced in the rainfall process flowing to the outlet of the partition, some runoff had not arrived at the outlet when most runoff water reached the outlet and was discharged from it. Therefore, when the delayed runoff reached the outlet, the effluent pollutant concentration slightly increased again.

\section{Linear Model of NPS Pollution Load Reduction Amount and Runoff Reduction Amount}

Due to the influence of NPS pollution and the rainfall-runoff process, the pollution load reduction amounts were closely related to the runoff reduction amount. If no runoff was produced on sunny or rainy days, the pollution caused was all point-source pollution in the study area. When there was a rainstorm and the surface runoff occured, both point source and NPS pollution could be concerned. Point source pollution was mainly composed of industrial drainage and domestic sewage, the amount of which produced by point source was relatively stable. Therefore, the change of point source pollution load was not considered when calculating. According to the water quantity and quality under different recurrence periods, the relationship of runoff reduction amount $(\Delta \mathrm{V})$ and four pollution load reduction amounts $(\Delta \mathrm{L})$ were established respectively. ( $\Delta \mathrm{V}$ is the total inflow-total outflow; $\Delta \mathrm{L}$ is the pollution load value of total inflow- the pollution load value of total outflow.) The linear model was established in the relationship of pollution load reduction amount and runoff reduction amount. And the methods of correlation coefficient test (R-value) and t-test (P-value) were used to judge the significance on $\Delta \mathrm{V}$ and $\Delta \mathrm{L}$. The results are shown in Fig. 7.

Table 7. Relative error of simulated and calculated values.

\begin{tabular}{|c|c|c|c|c|c|c|c|c|c|c|}
\hline \multirow{2}{*}{ Events } & \multirow{2}{*}{ Mode } & \multirow{2}{*}{$\begin{array}{l}\Delta \mathrm{V} \\
\left(\mathrm{m}^{3}\right)\end{array}$} & \multicolumn{8}{|c|}{$\Delta \mathrm{L}(\mathrm{kg})$} \\
\hline & & & SS & $\mathrm{R}$ & COD & $\mathrm{R}$ & $\mathrm{TP}$ & $\mathrm{R}$ & $\mathrm{TN}$ & $\mathrm{R}$ \\
\hline \multirow{4}{*}{$\begin{array}{c}3 \mathrm{a} \\
(3 \mathrm{~h})\end{array}$} & \multirow{2}{*}{ TD } & \multirow{2}{*}{352798} & 138118 & \multirow{2}{*}{$2.2 \%$} & 87564 & \multirow{2}{*}{$3.2 \%$} & 1530 & \multirow{2}{*}{$4.2 \%$} & 17596 & \multirow{2}{*}{$4.3 \%$} \\
\hline & & & 135122 & & 84870 & & 1469 & & 16865 & \\
\hline & \multirow{2}{*}{ LID } & \multirow{2}{*}{586925} & 144423 & \multirow{2}{*}{$-2.7 \%$} & 93590 & \multirow{2}{*}{$-2.9 \%$} & 1711 & \multirow{2}{*}{$-1.9 \%$} & 19876 & \multirow{2}{*}{$-0.6 \%$} \\
\hline & & & 148375 & & 96367 & & 1744 & & 19997 & \\
\hline \multirow{4}{*}{$\begin{array}{c}30 \mathrm{a} \\
(24 \mathrm{~h})\end{array}$} & \multirow{2}{*}{ TD } & \multirow{2}{*}{858471} & 155774 & \multirow{2}{*}{$-1.6 \%$} & 76558 & \multirow{2}{*}{$-2.9 \%$} & 1872 & \multirow{2}{*}{$2.1 \%$} & 18248 & \multirow{2}{*}{$2.2 \%$} \\
\hline & & & 158349 & & 78872 & & 1834 & & 17858 & \\
\hline & \multirow{2}{*}{ LID } & \multirow{2}{*}{120287} & 168516 & \multirow{2}{*}{$-5.3 \%$} & 87367 & \multirow{2}{*}{$-5.2 \%$} & 2156 & \multirow{2}{*}{$-3.9 \%$} & 22041 & \multirow{2}{*}{$-0.4 \%$} \\
\hline & & & 178015 & & 92141 & & 2244 & & 22134 & \\
\hline
\end{tabular}

Note: $\Delta \mathrm{V}$ is the reduction amount of the total runoff in study area, $\mathrm{m}^{3} ; \Delta \mathrm{L}$ the reduction amount of the pollution load in study area, $\mathrm{kg}$. $\mathrm{R}$ is the relative error of the simulated value and calculated value. 
It can be seen from the analysis in Fig. 7 that all the correlation coefficients are 0.59 or more, indicating that it has a great relationship of runoff reduction amount and
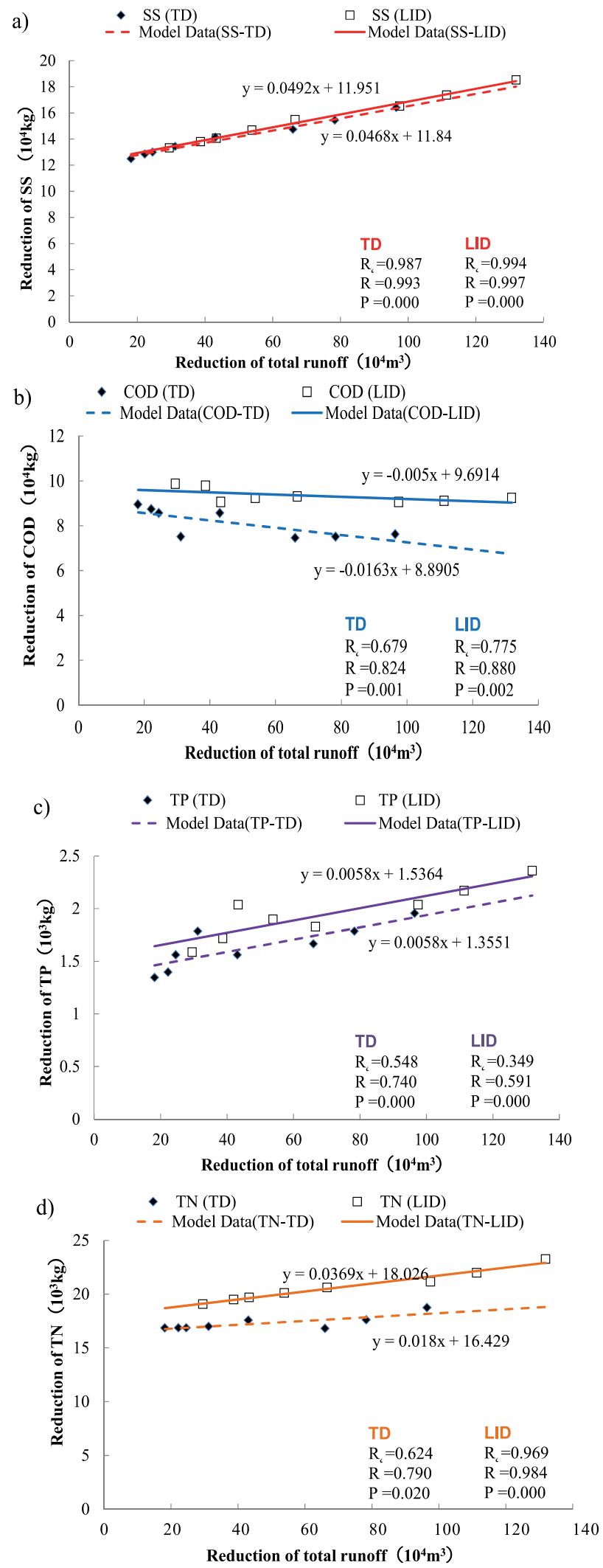

Fig. 7. Linear relationship model between $\Delta \mathrm{V}$ and $\Delta \mathrm{L}$ : a) SS, b) COD, c) TP, d) TN.
NPS pollution load reduction amount. According to the results of variance analysis, the $\mathrm{P}$ value of relationship for runoff reduction amount and TN reduction amount under TD mode is in the range of $0.01 \sim 0.05$, which indicates that the runoff reduction amount had a significant effect on the TN reduction amount. The $\mathrm{P}$ values of the other seven relationships are less than 0.01 , showing the extremely significant effects between $\Delta \mathrm{V}$ and $\Delta \mathrm{L}$. The pollution load reduction amounts increased while the total runoff reduction amount increased. At the conditions of the same total runoff reduction amount, the pollution load reduction amounts under LID mode were all greater than that under TD mode. Pollution load reduction amounts were positively correlated with runoff reduction amounts.

3 -year $(3 \mathrm{~h})$ and 30-year $(24 \mathrm{~h})$ recurrence rainfall were designed to verify the applicability of the fitting relationship to the research area by using the Chicago rainfall type. As Table 7 shows, the relative errors of the simulation and calculation results were $2.2-4.3 \%$ (TD) and $0.6-2.7 \%$ (LID) under 3-year recurrence rainfall, which were $2.2-4.3 \%$ (TD) and $0.6-2.7 \%$ (LID) under 30 -year recurrence rainfall. The results were reliable because the relative errors were all around 5\%. Thus, the fitting relationship in Fig. 7 can be used to represent the relationship between the non-point source pollution load and the total surface runoff in the study area. These results can be used to predict urban non-point source pollution load for a rainfall event or a given year, which can provide reference for the construction of sponge city and the reasonable plan of low-impact development.

\section{Conclusions}

The SWMM model was established by taking a sponge city as the study area. The rainfall type design of different rainfall events, as well as the hydrological and environmental effects of LID measures on the study area, were carried out.

The number of overflow nodes was positively correlated with the rainfall recurrence periods. After adding the LID combined facilities, the number of overflow nodes was reduced, the duration of waterlogging was shortened, and the time of flow peak was delayed. LID facilities could effectively control urban rainstorm runoff and reduce the peak flow, total runoff amount and pollution load. Under short duration rainfall events, total runoff reduction rates of LID mode compared with TD mode were increased by $24.7 \sim 48.9 \%$, while it was $18.3 \sim 22.3 \%$ under long-duration rainfall events. After adding the LID combined facilities, total amounts of SS, COD, TP and TN were reduced by $50.3 \sim 82.0 \%, 48.8 \sim 81.9 \%, 42.4 \sim 80.3 \%$, and $44.4 \sim 80.2 \%$ respectively. With the increase of rainfall recurrence periods, the reduction effects of runoff and pollution load amounts decreased, which was due to the fact that when the rainfall recurrence period was great, the LID facilities rapidly reached saturation status, and then 
the subsequent runoff reduction effects significantly decreased. The effluent concentration of pollutants decreased with the increase of rainfall recurrence periods. Compared with TD mode, the average effluent concentrations of SS, COD, TP and TN under LID mode were reduced by $13.5-36.8 \%, 11.3-36.3 \%, 7.9-30.7 \%$, and $7.1-30.4 \%$ respectively. The concentration removal effects of each indicator were ranked as $\mathrm{SS}>\mathrm{COD}>\mathrm{TP}$, $\mathrm{TN}$. The concentration removal effect of TP was greater than that of $\mathrm{TN}$ in short-duration rainfall events, while the opposite occurred in long-duration events. From the runoff and pollution loads under different recurrence periods, the relationship of runoff reduction amount and pollution load reduction amount was established. All the $\mathrm{P}$ values of eight relationships are less than 0.05 , which shows the significant effects between runoff reduction amounts and NPS pollution load reduction amount. For verifying the applicability of a fitted relationship, the rainfall events of 3 -year $(3 \mathrm{~h})$ and 30 -year $(24 \mathrm{~h})$ recurrence periods were adopted, and the results were reliability. The pollution load reduction amount was positively correlated with runoff reduction amount.

The SWMM model can effectively simulate the effect of LID combined facilities and quantify the simulation results of water quantity and quality. It has practical significance on the promotion and application of LID facilities. In this paper, LID measures have a good influence on regional hydrological and environmental effects, but they can be further optimized. The conditions in different areas and locations and different combinations of single LID measurements can be considered to achieve better runoff and pollution load control effect so as to provide a better basis for sponge city construction.

\section{Acknowledgments}

This research was financially supported by the National Natural Science Foundation of China (51879215) and the Key Research and Development Project of Shaanxi Province (2017ZDXM-SF-073).

\section{Conflict of Interest}

The authors declare no conflict of interest.

\section{References}

1. QIN H.P., LI Z.X., FU G.T. The effects of low impact development on urban flooding under different rainfall characteristics. Journal of Environmental Management, 129, 577, 2013.

2. KONG F.H., BAN Y.L., YIN H.W., JAMES P., DRONOVA I. Modeling stormwater management at the city district level in response to changes in land use and low impact development. Environmental Modelling \& Software. 95,132, 2017.
3. MARCAIDA A., NGUYEN T., AHN J. Investigation of Particle-Related Clogging of Sustainable Concrete Pavements. Sustainability, 10 (12), 4845, 2018.

4. JIA H.F., MA H.T., SUN Z.X., YU S.L., DING Y.W., LIANG Y. A closed urban scenic river system using stormwater treated with LID-BMP technology in a revitalized historical district in China. Ecological Engineering, 71, 448, 2014.

5. DAVIS A.P., TRAVER R.G., HUNT W.F., BROWN R.A., LEE R., OLSZEWSKI J.M. Hydrologic Performance of Bioretention Storm-Water Control Measures. Journal of Hydrologic Engineering, 17 (5), 604, 2012.

6. LI J.K, DENG C.N., LI Y., LI Y.J., SONG J.X. Comprehensive Benefit Evaluation System for LowImpact Development of Urban Stormwater Management Measures. Water Resources Management, 31 (14), 1, 2017.

7. GIRONÁS J., ROESNER L.A., ROSSMAN L.A., DAVIS J. A new applications manual for the Storm Water Management Model (SWMM). Environmental Modelling \& Software, 25 (6), 813, 2010.

8. LI Y., YU K., CHENG N.S., SHE M.X. Seven Stormwater Management Models in Low Impact Development. Guangdong Landscape Architecture, 38 (4), 9, 2016a [In Chinese].

9. KOUDELAK P., WEST S. Sewerage network modelling in Latvia, use of InfoWorks CS and Storm Water Management Model 5 in Liepaja city. Water \& Environment Journal, 22 (2), 81, 2010.

10. XING W., WANG H.Z., ZHAO D.Q., DONG L.Y. Introduction of System for Urban Stormwater Treatment and Analysis Integration Model. China Water \& Wastewater, 28 (2), 29, 2012.

11. WANG W.L., LI J.Q., GONG Y.W., ZHU M.J., ZHANG Q. K. LID Stormwater Control Effect Simulation Based on SWMM. China Water \& Wastewater, 28 (21), 42, 2012 [In Chinese].

12. LI J.K., LI Y., LI Y.J. SWMM-based evaluation of the effect of rain gardens on urbanized areas. Environmental Earth Science, 75 (1), 17, 2016b.

13. GUAN Y.H., MOU L., WANG C., YANG T.T. LID stormwater control effect and water quality simulation based on SWMM. China Rural Water \& Hydropower, 2017.

14. GONCALVES M.L.R., ZISCHG J., RAU S., SITZMANN M., RAUCH W., KLEIDORFER M. Modeling the effects of introducing low impact development in a tropical city: a case study from joinville, brazil. Sustainability, 10 (3), 728, 2018.

15. TSIHRINTZIS V.A., HAMID R. Runoff quality prediction from small urban catchments using SWMM. Hydrological Processes, 12 (2), 311, 2015.

16. LIU K.Y., WANG G.L. Comprehensive water resources evaluation method of water quantity and quality. Hydrology, 22 (3), 32, 2002 [In Chinese].

17. WANG K.H., ALTUNKAYNAK A. Comparative Case Study of Rainfall-Runoff Modeling between SWMM and Fuzzy Logic Approach. Journal of Hydrologic Engineering, 18 (5), 283, 2013.

18. FU R., LUO L. H., LIU J., ZHAO H. The Application of the Drains System Capability Assessment Based on SWMM. China Rural Water \& Hydropower, (3), 103, 2015 [In Chinese].

19. KEIFER C.J., HUNG C.Y., WOLKA K. Modified Chicago Hydrograph Method. Storm Sewer Design, 1978.

20. CEN G.P., SHEN J., FAN R.S. Research on Rainfall Pattern of Urban Design Storm. Advances in Water Science, 9 (1), 41, 1998 [In Chinese]. 
21. ROSSMAN L.A. Storm water Management Model User's Manual Version 5.0.USEPA. EPA/600/R-05/040. 2010.

22. MORRIS M.D. Factorial Sampling Plans for Preliminary Computational Experiments, Technometrics, 33 (2), 161, 1991.

23. SHARIFAN R.A., ROSHAN A., AFLATONI M., JAHEDI A., ZOLGHADR M. Uncertainty and Sensitivity Analysis of SWMM Model in Computation of Manhole Water Depth and Sub-catchment Peak Flood. Procedia - Social and Behavioral Sciences, 2 (6), 7739, 2010.

24. SHI R., PANG B., ZHAO G., DU L.G., ZHONG Y. D., ZUO P. Analyzing parameter sensitivity for the SWMM model in urban srorm water simulation. Journal of Beijing normal University (natural science edition) (5), 456, 2014. [In Chinese].

25. LI C.L., HU Y.M., XU Y.Y., SUN F.Y., CHEN T. Local sensitivity analysis of parameters in Stormwater Management Model, Chinese Journal of Ecology, 33 (4), 1076, 2014 [In Chinese].
26. Beijing Municipal Administration Design and Research Institute. Handbook of concise drainage design. China building industry press, 1990 [In Chinese].

27. LI J.K., DENG C.N, LI H.E., MA M.H., LI Y.J. Hydrological Environmental Responses of LID and Approach for Rainfall Pattern Selection in Precipitation Data-Lacked Region. Water Resources Management, 32 (10), 3271, 2018.

28. WANG W.W., ZHAO Z.J., QIN H.P. Hydrological Effect Assessment of Low Impact Development for Urbanized Area Based on SWMM. Peking University, 48(2), 303, 2012 [In Chinese].

29. PAN G.Y., XIA J., ZHANG X., WANG H.P., LIU E.M. Research on Simulation Test of Hydrological Effect of Bio-retention Units. Hydroelectric energy science, 30 (5), 13, 2012 [In Chinese]. 